\title{
NA BATALHA E NA MILITÂNCIA: O COTIDIANO DE PROSTITUTAS NO BAIRRO DA CAMPINA, BELÉM-PA.
}

Silvia Lilia Silva Sousa ${ }^{1}$

O ensaio apresentado é resultado da dissertação "Memórias das Esquinas: as trajetórias de prostitutas na batalha pelo bairro da Campina Belém, PA” (Sousa, 2017) aliado às minhas experiências enquanto colaboradora no GEMPAC ${ }^{2}$ (Grupo de Mulheres Prostitutas do Pará). A partir das imagens apresentadas aqui volto meu olhar as formas sensíveis pelas quais as prostitutas praticam o bairro da Campina a partir da militância e da batalha ${ }^{3}$.

O bairro da Campina é uma das áreas mais antigas de prostituição da cidade de Belém. De acordo com o historiador e antropólogo José Ronaldo Trindade (1999) é possível encontrar já em jornais do século XIX a presença de prostitutas no bairro, constantemente denunciadas por perturbarem a ordem e propagarem práticas consideradas ofensivas à moral e à saúde pública. Segundo José do Espírito Santo Júnior (2013), em 1921 foi delimitada uma área reservada especialmente ao meretrício, também conhecida como Quadrilátero do Amor. Neste sentido, delimitar uma área reservada às práticas da prostituição se constituiu enquanto estratégia de controle dos corpos (De Certeau, 1998; Foucault, 2011) perpetuadas, sobretudo, a partir de práticas de higienização frente aos espaços destinados ao meretrício espalhados pela cidade de Belém, em especial, no bairro da Campina.

\footnotetext{
${ }^{1}$ Universidade Federal do Pará, Brasil.

${ }^{2}$ Entidade Não Governamental fundada em 1991 com objetivo de organizar as trabalhadoras sexuais na luta contra o estigma e violência.

${ }^{3}$ Batalha é um termo utilizado pelas prostitutas entrevistadas que significa o momento em que estão trabalhando na prostituição. É importante compreendermos que a batalha estabelece redes de sociabilidades, laços afetivos entre as prostitutas, com os clientes e com o próprio bairro. A batalha é compreendida aqui como uma das múltiplas formas de praticar o bairro da Campina.
} 


\section{A localização do meretricio}

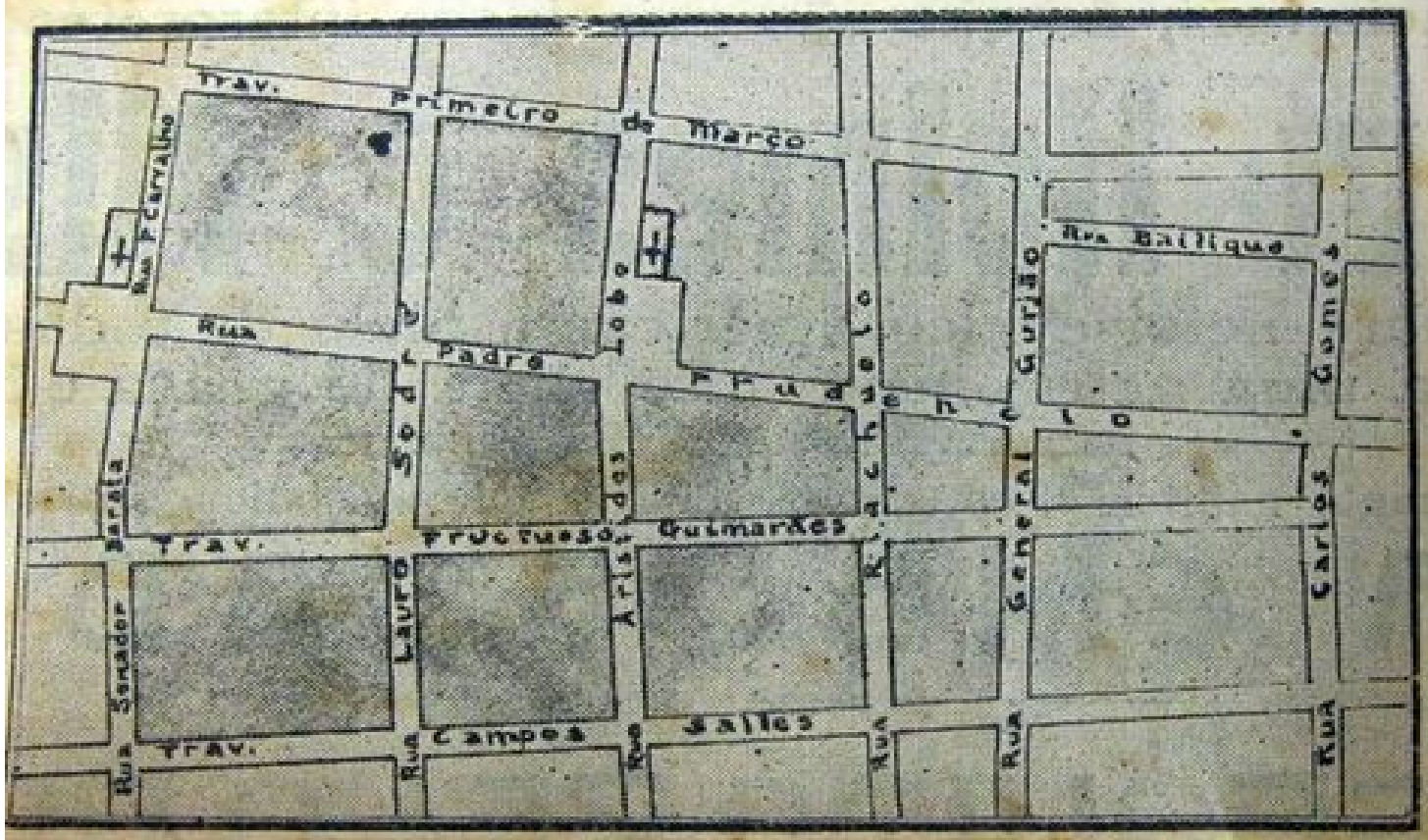

Croquis representando o bairro onde provavelmente serão localizadoa os prostibulos de Belem, de accôrio com o pensamento do sr. desembargador Julio Costa, chefe de policia, no intuito louvavel de sanear o resto da cidade do contagio das innumeras pocilgas espalhadas nas differentes ruas desta capital.

No ano de 1970, período de intensa violência e repressão direcionadas de forma cruel e desumana à mulheres prostitutas - constantemente estupradas e obrigadas a lavar os salões policiais - a zona da Campina foi interditada. Sob a ordem do até então governador, Alacid Nunes, diversas casas de prostituição tiveram suas portas fechadas, prostitutas foram deportadas para regiões periféricas de Belém ${ }^{4} e n q u a n t o$ outras ficaram presas nos prostíbulos sob pena de prisão, estupros e torturas.

Figura 1- Localização da Zona do Meretrício de Belém. Imagem retirada da internet ${ }^{5}$.

\footnotetext{
${ }^{4}$ De acordo com Lourdes Barreto (prostituta fundadora da Rede Brasileira de Prostitutas e Coordenadora do GEMPAC, referência mundial na luta contra a Aids) durante a interdição da zona muitas mulheres foram deportadas para o município de Ananindeua, mais especificamente para o bairro da Cidade Nova.
} 


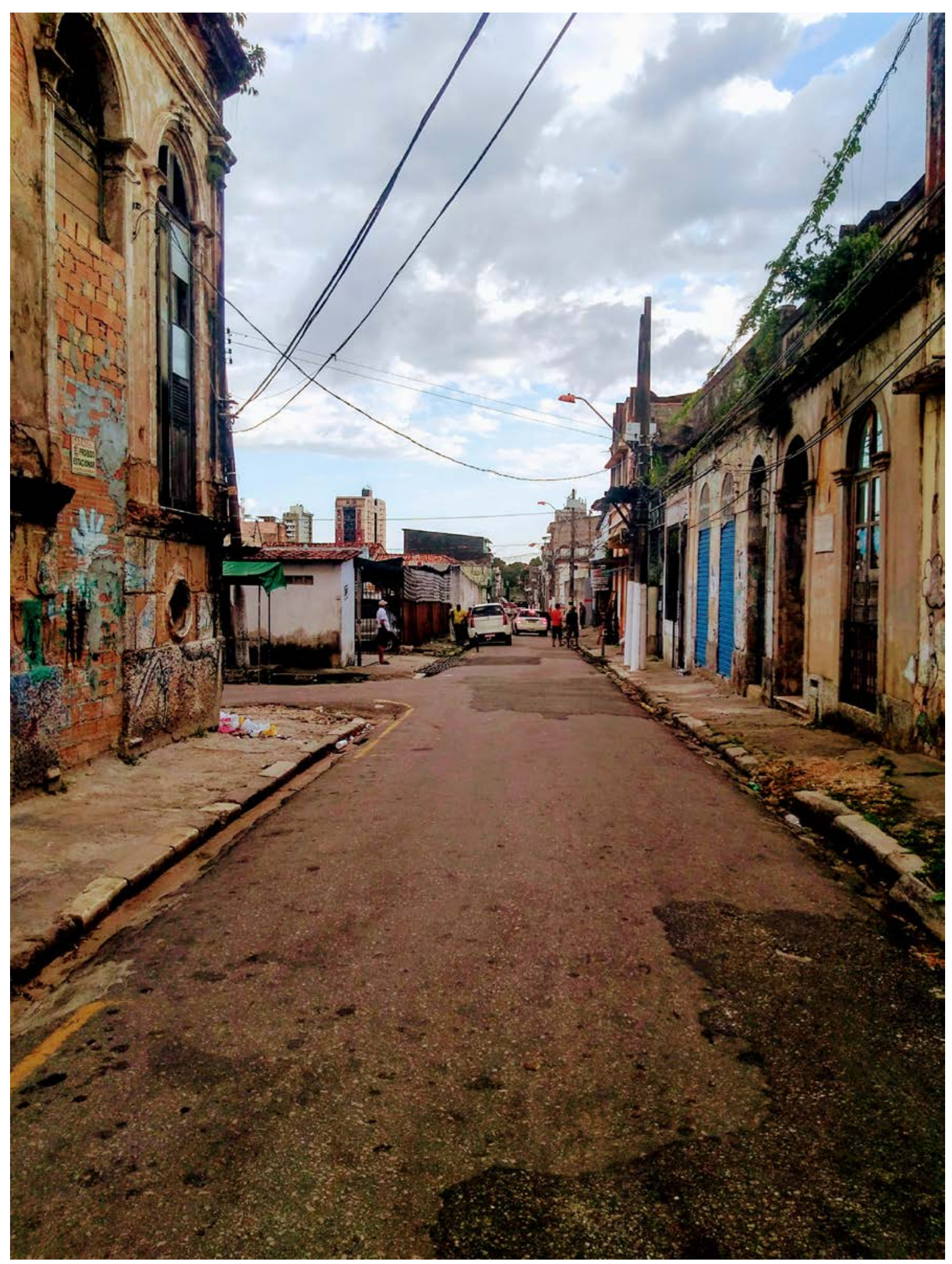

Figura 2- Rua General Gurjão, locus histórico de prostituição. Foto Silvia Sousa, 2018.

\footnotetext{
${ }^{5}$ Imagem retirada do site: www.pinterest.es.
} 
Ao adentrar neste universo a partir da pesquisa etnográfica percebo formas heterogêneas de organização junto aos espaços do bairro, e diferentes relações e performances produzidas no cotidiano da zona. Sentadas entre as calçadas, em cadeiras plásticas, caminhando entre as esquinas, ou mesmo, na militância junto ao GEMPAC estas mulheres configuram paisagens diversas (Silveira, 2009, 2016), modificam os espaços da urbe e criam táticas (De Certeau, 1998) de permanência no bairro conhecido como a mais famosa das zonas de prostituição da cidade de Belém. 


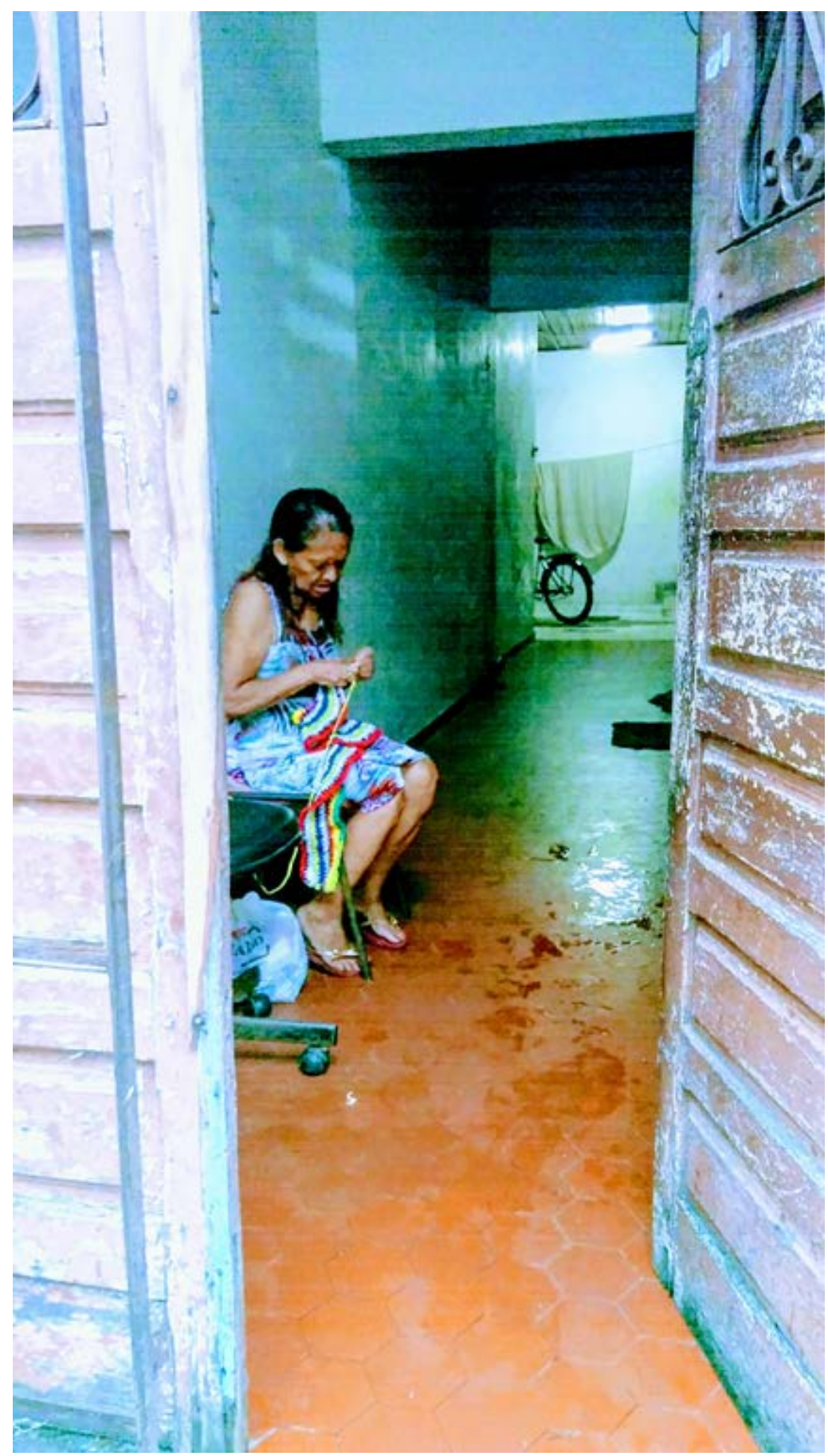

Figura 3 - À espera do cliente: outras performances na batalha. Foto Silvia Sousa, 2017. 


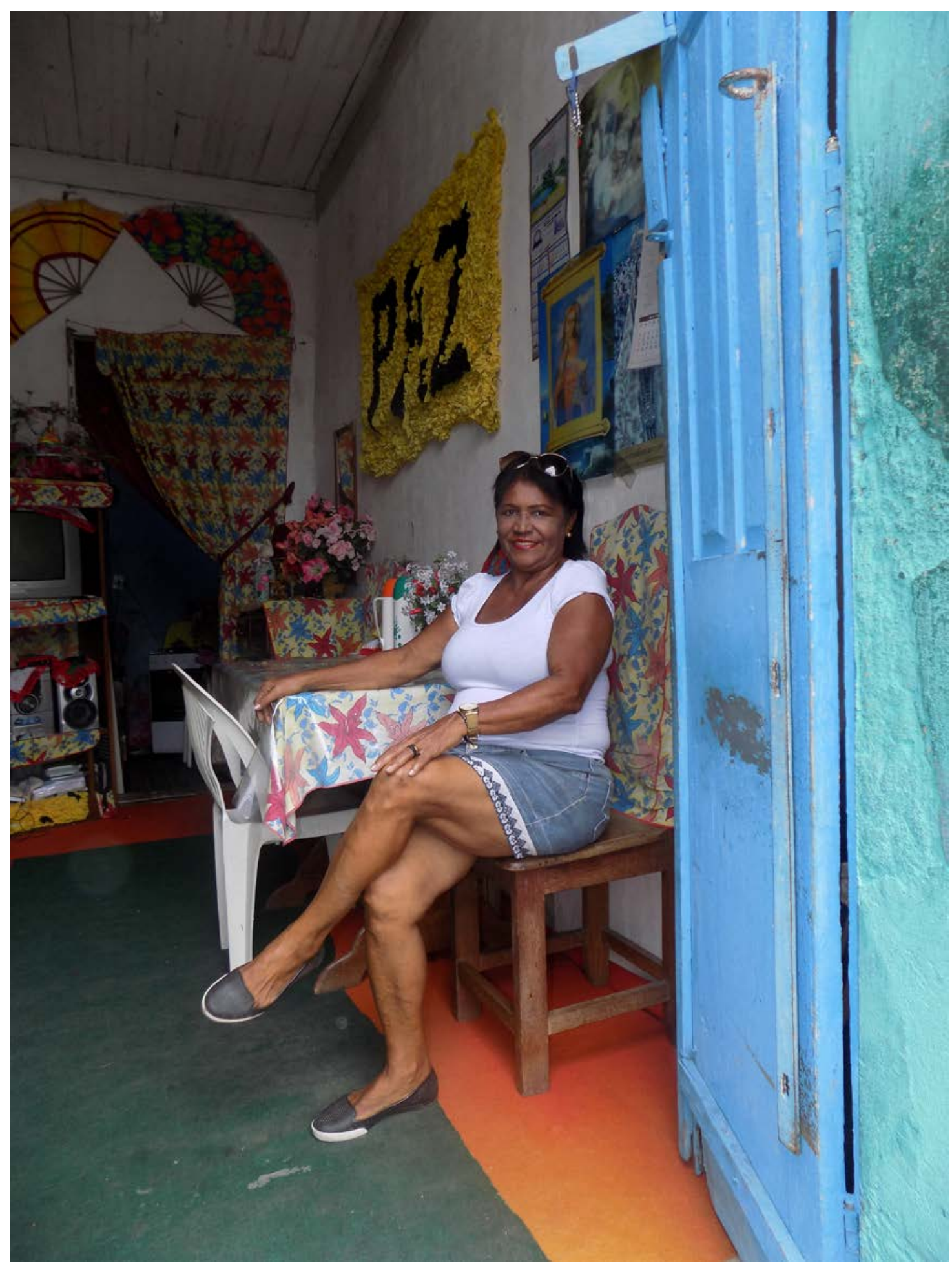

Figura 4-Cinderela ${ }^{6}$ numa casa de prostituição do bairro. Foto Silvia Sousa, 2016.

\footnotetext{
${ }^{6}$ Eunice, mais conhecida como Cinderela é militante do movimento de prostitutas e batalha há mais de 30 anos no bairro da Campina.
} 

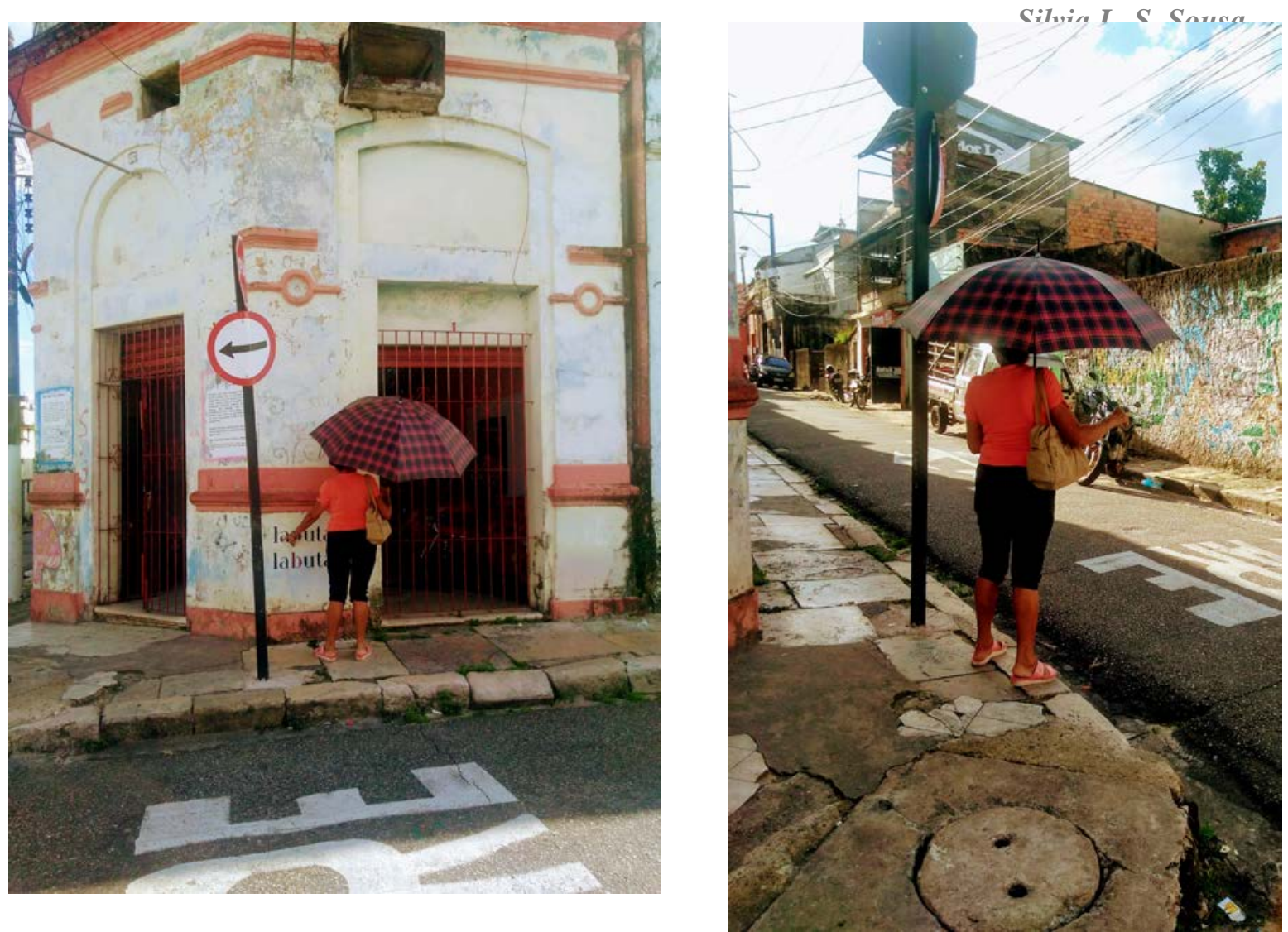

Figuras 5 e 6- La Puta Labuta. Prostituta em seu ponto na Rua Padre Prudêncio, bairro da Campina. Foto Silva Sousa, 2018. 


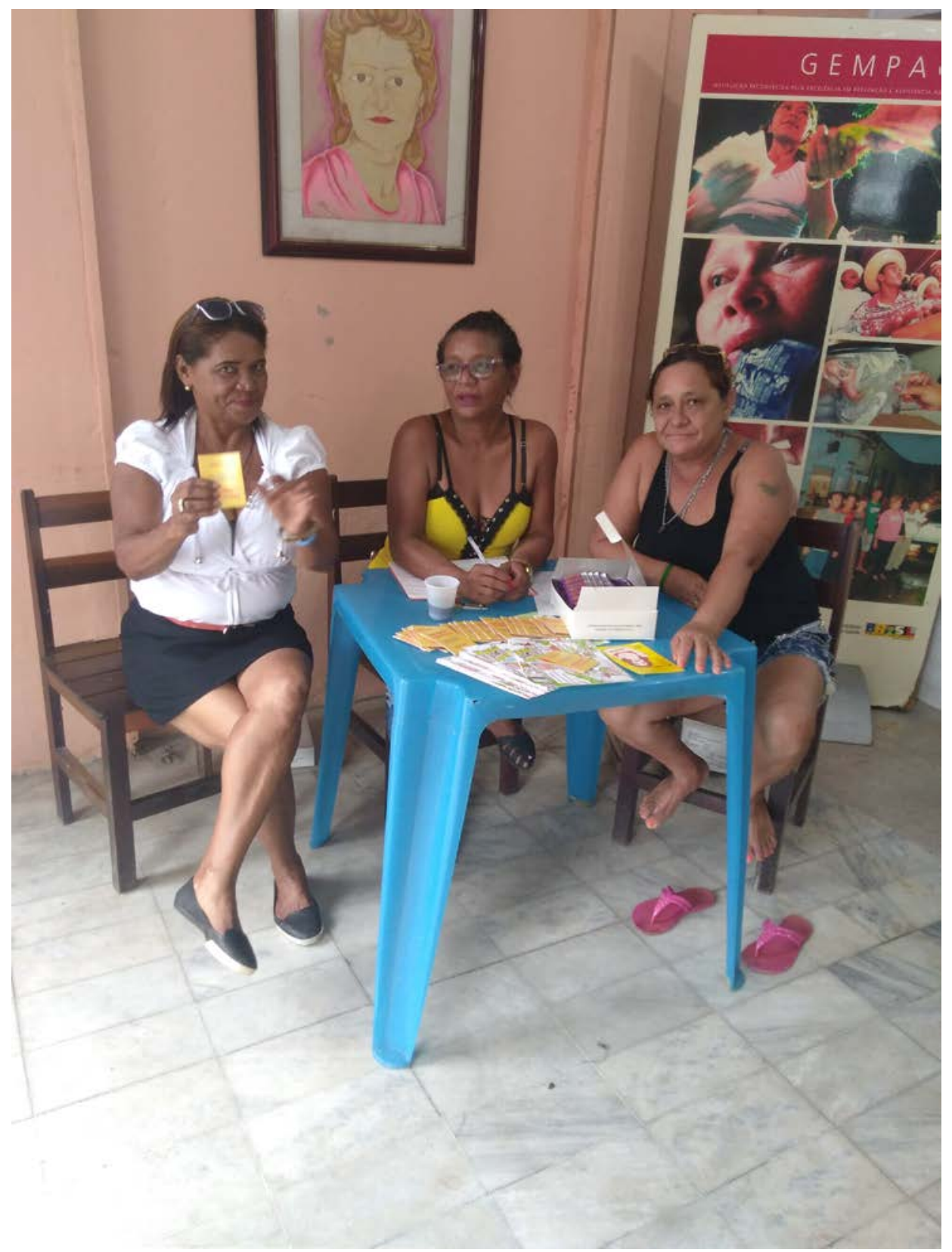

Figura 7 - Entrega de preservativos durante o programa formativo informativo. Foto Silvia Sousa, 2018. ${ }^{7}$

\footnotetext{
${ }^{7}$ Da esquerda para direita: Cinderela, Vitória e Maria Silva. Militantes do movimento de prostitutas. Todas compõem o colegiado do GEMPAC.
}

Iluminuras, Porto Alegre, v. 19, n. 47, p. 278-290, dec, 2018. 


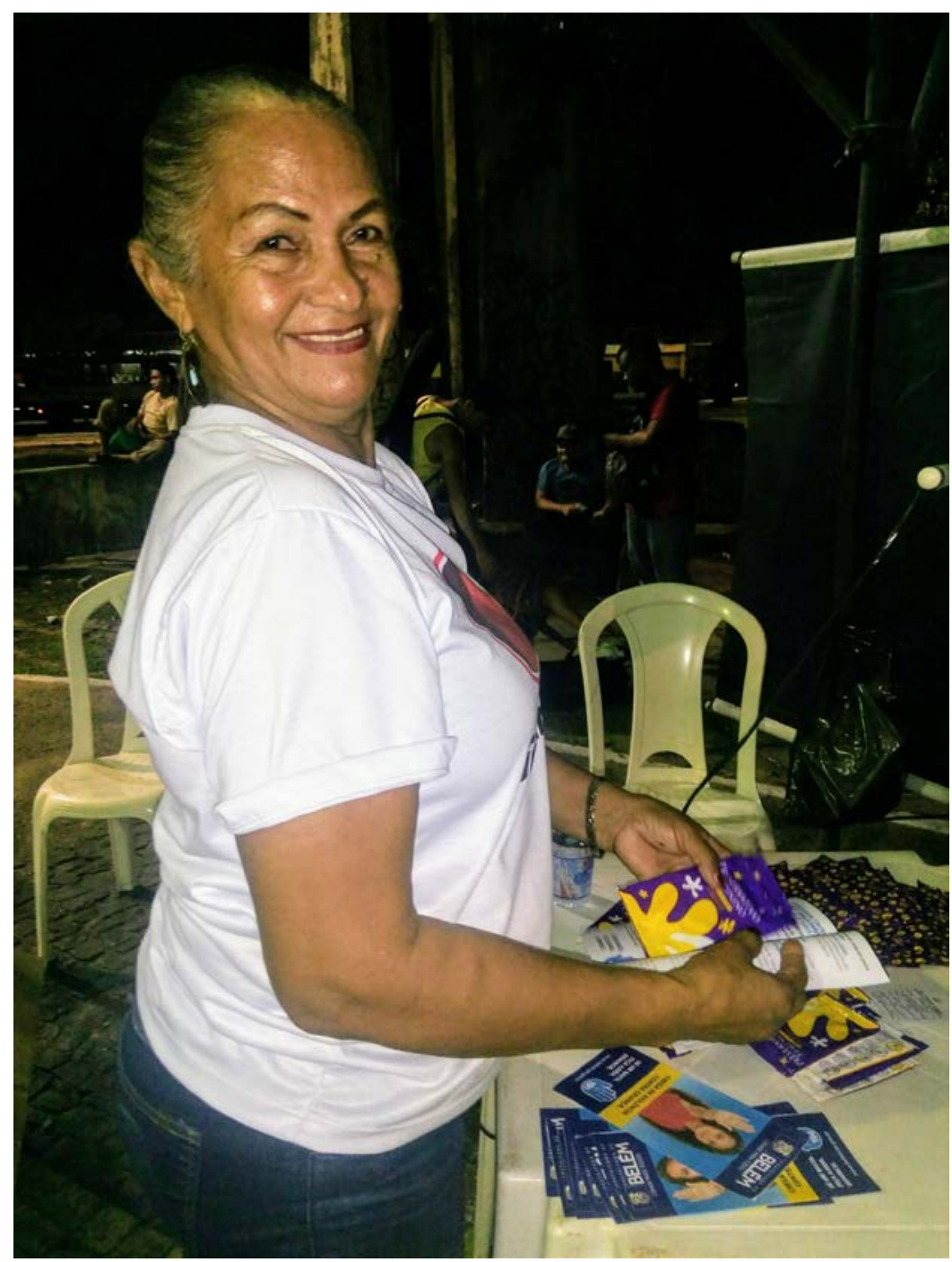

Figura 8: Entrega de preservativos (Maria Rita) ${ }^{8}$. Foto Silvia Sousa, 2018. Foto Silvia Sousa, 2018

\footnotetext{
${ }^{8}$ Militante do movimento de prostitutas, componente do colegiado do GEMPAC.
} 


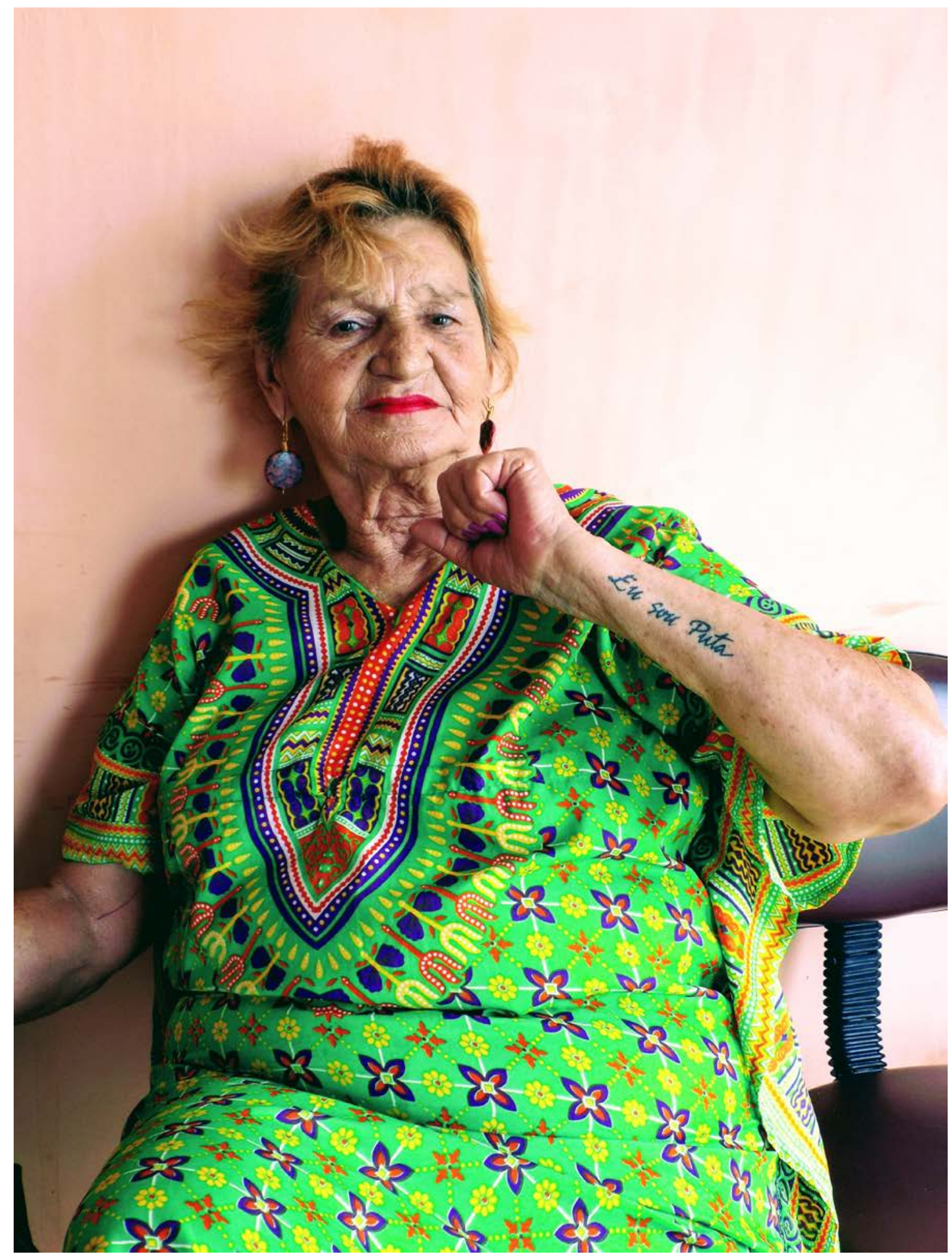

Figura 9: Eu sou puta! Lourdes Barreto. Foto Silvia Lilia, 2017. 


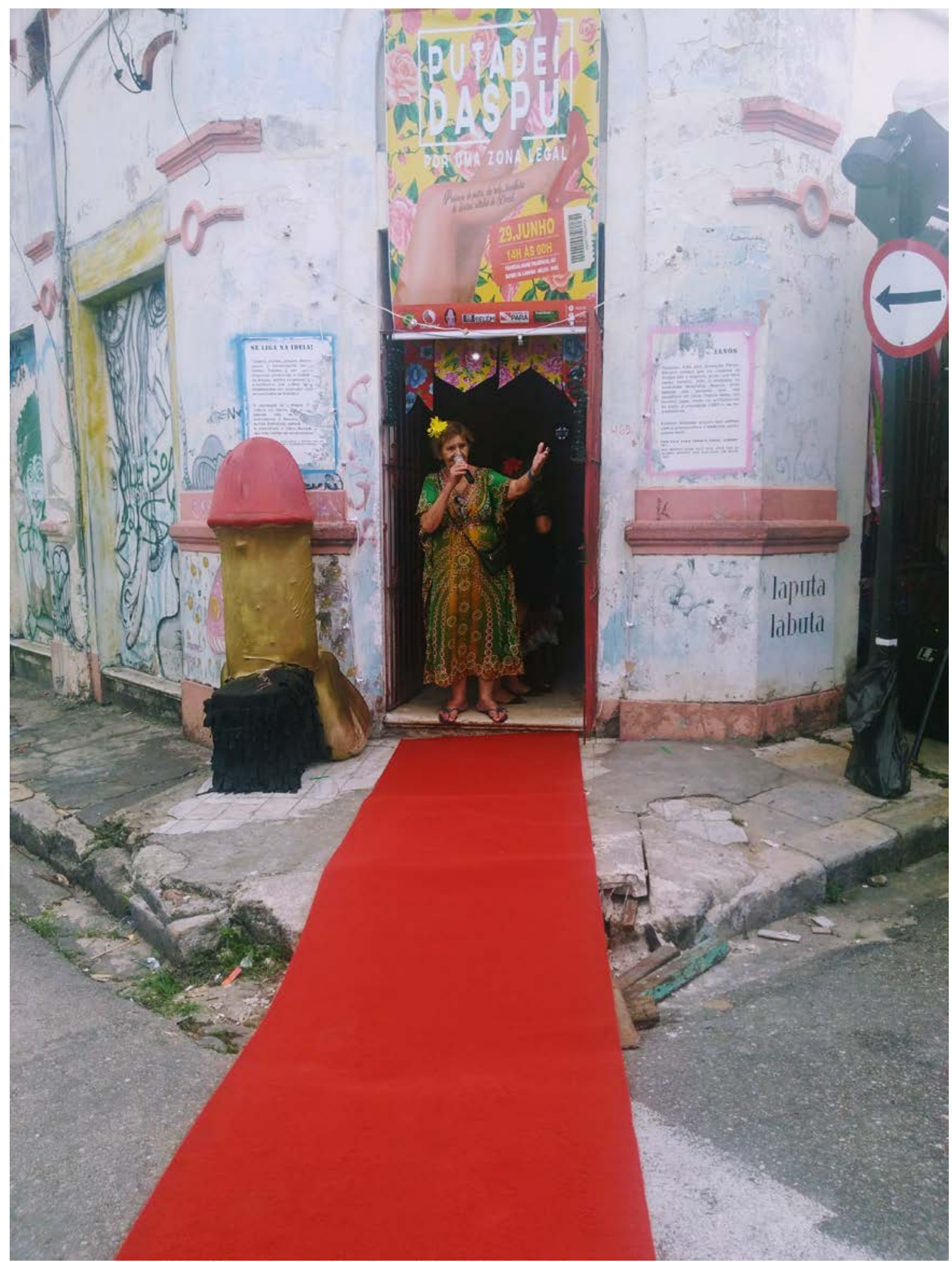

Figura 10 - Lourdes Barreto na abertura do evento Puta Dei DASPU $2018^{9}$

\footnotetext{
${ }^{9}$ Evento de incidência política criado pelo GEMPAC no ano de 2012 em comemoração ao Dia Internacional da Mulher Prostituta.
}

Iluminuras, Porto Alegre, v. 19, n. 47, p. 278-290, dec, 2018. 
Além do lugar da batalha, a Campina é também um espaço de luta política significativa para o movimento de mulheres prostitutas, pois além abrigar a sede do GEMPAC - uma das instituições mais importantes que compõem o movimento de mulheres prostitutas e a Rede Brasileira de Prostitutas ${ }^{10}$ - este bairro é um lugar histórico da luta pelo direito humano de ser puta (Olivar, 2007).

A zona compreendida aqui enquanto lugar praticado (Tuan, 1983; De Certeau, 1998) nos leva a pensar nas relações afetivas que estas mulheres mantém com o bairro (Sousa, 2017). Seja a partir da batalha ou da militância, as putas que praticam a Campina também produzem poéticas (Bachelard,1978) sobre ela. É na prática sensível do cotidiano citadino, em meio a uma multidão de pessoas que cruzam suas ruas, travessas e avenidas, que as putas desnudam este corpo fêmea ${ }^{11}$ chamado Campina.

\section{Referências}

BACHELARD, Gaston. “A poética do espaço”. São Paulo: Abril Cultural, 1978.

DA SILVEIRA, Flávio. L. A.; CANCELA, Cristina Donza. Paisagem e Cultura: Dinâmicas do patrimônio e da memória na atualidade. Belém: EDUFPA, 2009.

DA SILVEIRA, Flávio. L. A. As dinâmicas das paisagens de Belém (PA): memórias, ruínas, e imaginários no mundo urbano.In ANDRADE, R.(Org). Amazônias, cidades e jardins: anatomia urbana e identidades paisagísticas. Rio de Janeiro. UFRJ,2016 DE CERTEAU, Michel. A Invenção do Cotidiano. Artes de fazer. V. I. Rio de Janeiro: Vozes, 1994.

ESPÍTO SANTO JÚNIOR, José. Entre Cabarés e Gafieiras: Um estudo das Representações boemias na periferia de Belém do Pará, 1960-1980. Originalmente apresentada como tese de doutorado pela Pontifícia Universidade Católica de São Paulo, São Paulo, 2013.

FOUCAULT. Michel. A História da Sexualidade I. São Paulo: Paz e Terra, 2014.

OLIVAR, José. M. N. O Direito Humano de ser Puta: uma reflexão sobre Direitos sexuais no universo da prostituição Feminina em Porto Alegre. Teoria e Sociedade. $\mathrm{n}^{\mathrm{o}}$ 15.2 - julho- dezembro de 2007 p. 108-137.

\footnotetext{
${ }^{10}$ Rede de mulheres prostitutas que integra diversas instituições de prostituas do Brasil, acadêmicos e colaboradores, criada em 1987 com o objetivo de constituir um movimento pelos direitos das profissionais do sexo.

${ }^{11}$ A ideia de "corpo fêmea” parte das reflexões de Lourdes Barreto, prostituta que chegou no bairro na década de 50 do século XX, e tem sua trajetória de vida ligada ao bairro da Campina. Lourdes é fundadora da Rede Brasileira de prostitutas, coordenadora do GEMPAC e uma das principais lideranças do movimento de mulheres prostitutas.
} 
SOUSA, Silvia. L. S. Memórias das Esquinas: as trajetórias de prostitutas na batalha pelo bairro da Campina, Belém, PA. Originalmente apresentada como dissertação de mestrado no Programa de Pós-Graduação em Sociologia e Antropologia, UFPA, Belém, 2017.

TRINDADE, José. R. Errantes da Campina. Belém: 1800-1900. 1999.193 f. Originalmente apresentada como dissertação de mestrado em História Social. Instituto de Filosofia e Ciências Humanas, Faculdade de História, Universidade Federal Do Pará, Belém.1999.

TUAN, Yi- Fu. Espaço e lugar. A perspectivada experiência. São Paulo: Difel, 1983.

VELHO, Gilberto. Projeto e Metamorfose: antropologia das sociedades complexas. Rio de Janeiro: Jorge Zahar Ed., 1994.

Recebido 09 de setembro 2018

Aprovado 15 de dezembro 2018 